\title{
Monitoring Corals from Rescue to Care with ArcGIS and Flickr
}

\author{
Deborah James ${ }^{\text {a }}$ \\ Keywords: florida reef tract, stony coral tissue loss disease, geographic information system, flickr, documentary media, coral restoration, ethics of care, arcgis \\ https://doi.org/10.1525/001c.18859
}

\begin{abstract}
This article intervenes in disaster media research by investigating the complex system of mediation that is required to mitigate coral disease and to monitor coral rescue and care. Stony coral tissue loss disease, discovered in 2014, has rapidly infected more than 50 percent of the Florida Reef Tract, the only living barrier reef in the continental United States. In response, reef managers have established a coral rescue team tasked with carrying out a phased coral rescue plan. In conjunction with that plan, the Coral Rescue-Coral Monitoring Dashboard interface and a corresponding Coral Rescue photo series hosted on Flickr were launched in 2019. This article explores the Dashboard and the Flickr photo series together as a single form of media introduced and discussed as "intermediation monitoring." As a dynamic human-animal interface where coral tissue emerges, the Dashboard materializes coral agency and instantiates protocols for care: collection, gene sampling, and preparation for housing and transport to landbased aquarium facilities. The article further demonstrates how complex systems can be connected to one another-Dashboard to photos, technological system to the system of living things, and complex coral systems to human systems-in order to produce the mutually constitutive human-animal relationship between corals and humans as caregivers across the corals' lives. Also emphasized are the ways that digital animal-human interfaces can be used to enact disaster relief.
\end{abstract}

On a recent volunteer coral restoration dive trip in Key Largo, I spent an afternoon tying finger-length staghorn coral fragments to a Coral Tree ${ }^{\mathrm{TM}}$, a PVC pipe structure suspended between the ocean floor and the surface. After a morning of training at the Coral Restoration Foundation (CRF) Education Center, I completed two ocean nursery dives, attaching corals taken from a genotyped crate of staghorn coral fragments to a corresponding tree. Based on scientific studies of genetic diversity among corals, the careful assignment of particular corals to particular trees ensures the integrity of the nursery management system. By keeping different genotypes separate, the CRF reef managers can identify which coral genotypes show resistance to disease, temperature fluctuation, and pollution (Bicker 2019). After six or so months in the nursery, these healthy, resilient corals are strategically outplanted to reef sites with genetically diverse corals, which are site mapped and monitored. The careful planning and nurturing are paying off: during the August 2020 full moon, nursery-raised staghorn coral outplants were observed spawning in the wild and were documented for the first time in the Florida Keys (REEFocus 2020). This spawning event further opens the door to large-scale restoration of the Florida Reef Tract, a 358-mile barrier reef running along the Atlantic

\footnotetext{
a Deborah James is an Associate Professor of Media Studies at Governors State University. She holds a Ph.D. in Communication from Wayne State University, focusing on human rights documentary and women's production practices. She earned her M.A. in Media Studies from the New School for Social Research, focusing on digitally mediated personal narratives and social media. Her work examines coral restoration practice to understand how documentary and digital media enable humans to care for corals and reefs.
} 


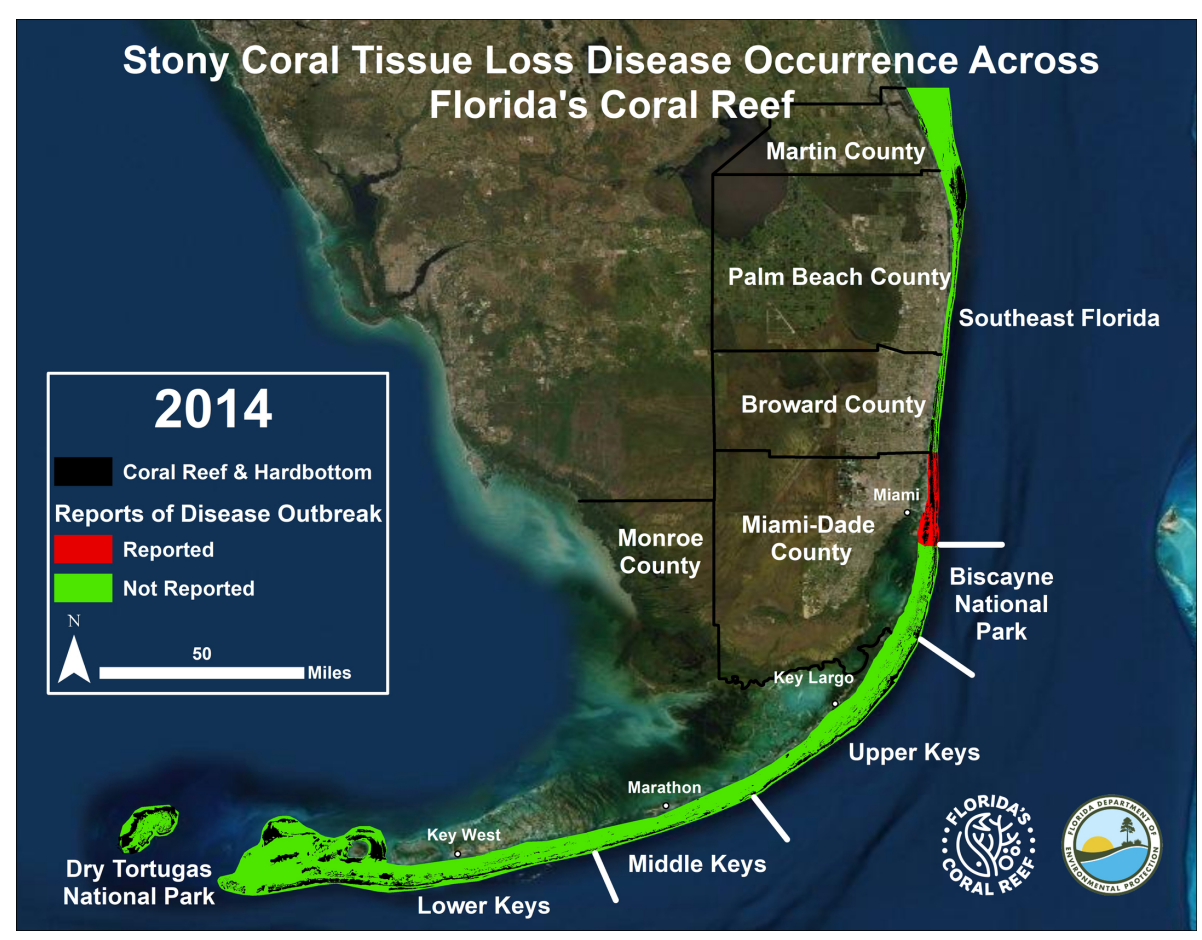

Figure 1a: Time series animation showing the progression of stony coral tissue loss disease. Graphic updated September 16, 2020.

Source: Florida Department of Environmental Protection.

Ocean side of the Florida Keys. Observable from space, the stony-animal-plant Florida Reef Tract structure is the backbone of a connected system of extraordinarily diverse and productive habitats (Keller and Wilmot 2008).

Stony coral tissue loss disease (SCTLD) was first observed in 2014. Since then, it has rapidly spread both north and south, infecting much of the Florida Reef Tract (figure 1), the only living barrier reef in the continental United States. According to the Florida Keys National Marine Sanctuary (hereafter referred to as the Sanctuary), this event is unique for its "geographic range, duration, progression, high rates of mortality, and the number of animals affected" (Parsons n.d.). On top of this, the remaining corals are continually stressed by temperature fluctuations and weather events caused by anthropogenic climate change. It became evident that under these conditions, the corals would be unable to maintain species diversity or genetic diversity in the wild. However, there was growing evidence for an effective intervention: coral restoration nursery operations that would maintain corals for propagation, outplanting, gene banking, and relatively comprehensive ongoing monitoring.

In light of evidence for effective intervention, the Florida Fish and Wildlife Conservation Commission and its partner, the National Oceanic and Atmospheric Administration (NOAA), "made the unprecedented decision to remove healthy corals from the wild ahead of the disease front to conserve and protect the genetic diversity of Caribbean coral species" (Florida Fish 


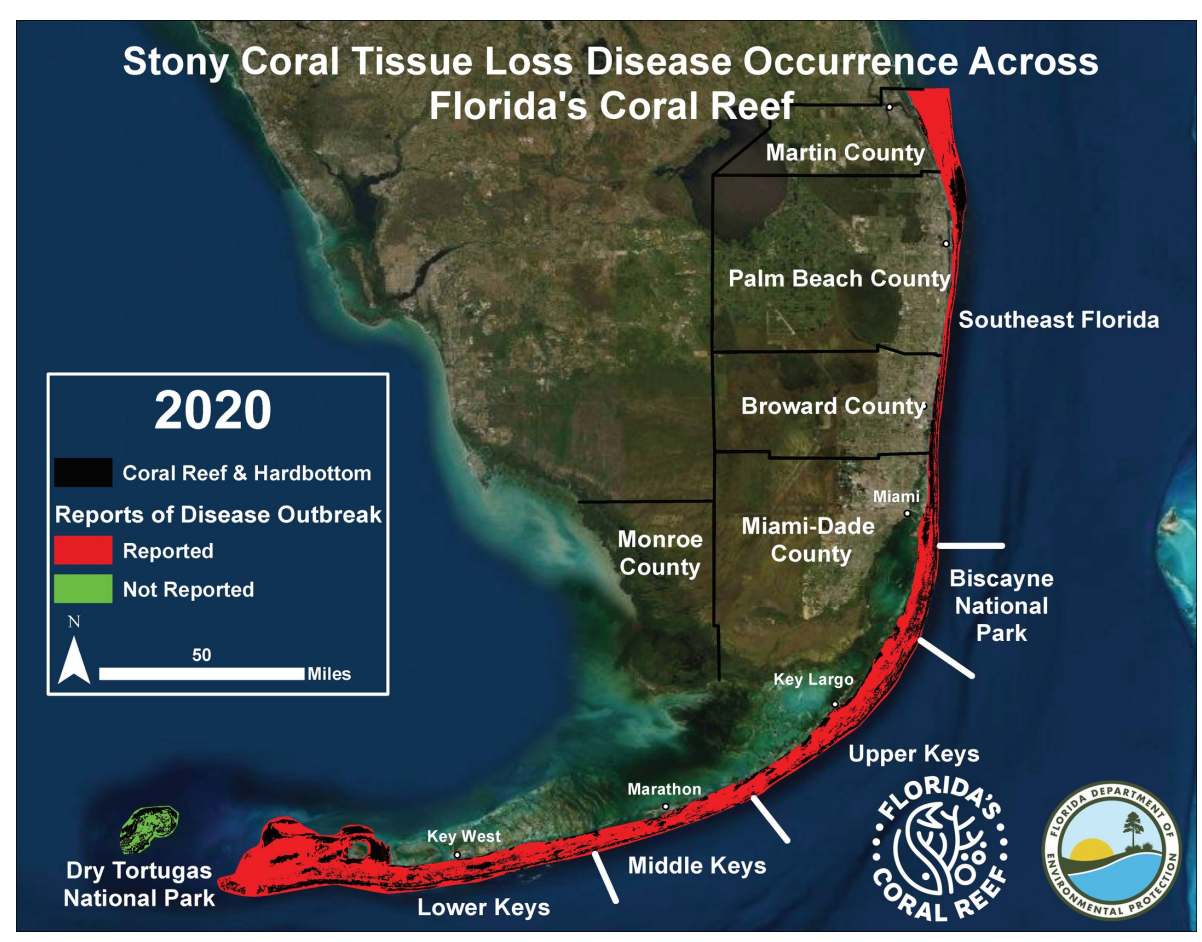

Figure 1b: Time series animation showing the progression of stony coral tissue loss disease. Graphic updated September 16, 2020.

Source: Florida Department of Environmental Protection.

and Wildlife Conservation Commission n.d.). Signaling that this threat to the reef was thought of as a kind of natural disaster, the commission and NOAA created a disease response plan that reconfigured resources, prioritizing the rescue, documentation, housing, and monitoring of healthy corals in accredited facilities across the United States to restore the reef once the disease has passed.

As a part-time resident of Tavernier Key with a family that at different times operated a small vacation motel and a lobster business, I first personally encountered the Florida Reef at Hens and Chickens Sanctuary Preservation Area, where I learned to snorkel at the age of six. Snorkeling and scuba diving on this reef tract, and the ocean-dependent work of my family, shaped my relationship with this natural place. After more than a decade away from Florida, I returned in 2014 during a break from my position as a media studies professor. Over multiple dives off Key West and Key Largo, I was dismayed to see the flat gray rubble of dead corals in place of the familiar bright and multidimensional corals of olive green, blue-gray, and golden yellow.

As a nonscientist, my first step was to understand the animal research protocols and monitoring used in coral work by starting with the work of those who are closest to the corals: research scientists. In 2016 I accepted my first appointment to Governors State University's Institutional Animal Care and Use Committee as its nonscientific member to understand federal guidelines for the use of animals in scientific research. I contributed to the review of the 
campus animal care and use program and of new facilities, including a field station, as well as the review and approval of research protocols. I also began to travel to the Keys to attend Sanctuary Advisory Committee meetings and talk to reef managers. In December 2018 I attended the first Coral Futures symposium on coral restoration and intervention science, held in Key Largo. As I observed from a position of immersion in this environment, the use of media for the monitoring of corals as a practice of care by restoration scientists and reef managers resonated with me. It was then that I realized how the monitoring of live genotyped corals function as a mediated process that enables the corals to be understood, and I began to formalize these observations.

As a media researcher invested in exploring documentary as both community practice and a form of humanitarian action, I decided to try to understand what was happening and to present this analysis of the mediated aspects of coral restoration. The Coral Rescue-Coral Monitoring Dashboard (referred to in this article as the Dashboard) is a public-facing website interface that provides information about reassembled coral data collected from field rescue and care operations using the Esri ArcGIS mapping and analytics platform. In keeping with the theme of this stream of the journal, I see the coral disease and the Dashboard as situated at the intersection of disaster, media, and relief. Conceptually speaking, if "disaster media" "names the project of attuning to ways that media are both complicit in the amplification of disastrous occurrence and helpful in the provision of reckoning and relief, support and succor" (Parks and Walker 2020), then the use of mediated means to study and intervene in coral health on Florida's Atlantic coast constitutes an instance of disaster media that inclines toward disaster relief while raising important questions of human-nonhuman relationships of care.

\section{Digital Form Follows Coral Function}

The Coral Rescue-Coral Monitoring Dashboard was built in 2019 and launched as part of the larger collaborative disease response, designed to monitor the rescued corals' vital signs. The Dashboard retains the integrity of the separate genetic data on coral species and genotypes, mapping them discretely on its digital reef, a replication of coral diversity in the wild. This approach is based in part on the CRF's "genetically conscious" restoration work ("Genetic Bank." n.d.). The Dashboard (see figure 2) assembles the field data recorded for each coral colony collected from a specific reef site, enabling researchers to track and monitor the corals through the entire process from rescue to care. Individualizing corals in care at multiple facilities, the Dashboard is a medium that extends our "naked eye" "towards a more expansive experience of self and the agendas of that self, a more expansive, ethically based subjectivity" (Summerhayes 2015, 19). This process is documented in the Coral Rescue photo series, posted to Flickr (n.d.). Using digital cameras that record exchangeable image file format (EXIF) data, rescue team members documented the processes of collection, gene sampling, preparation, and transportation. From observation to field reports to the 


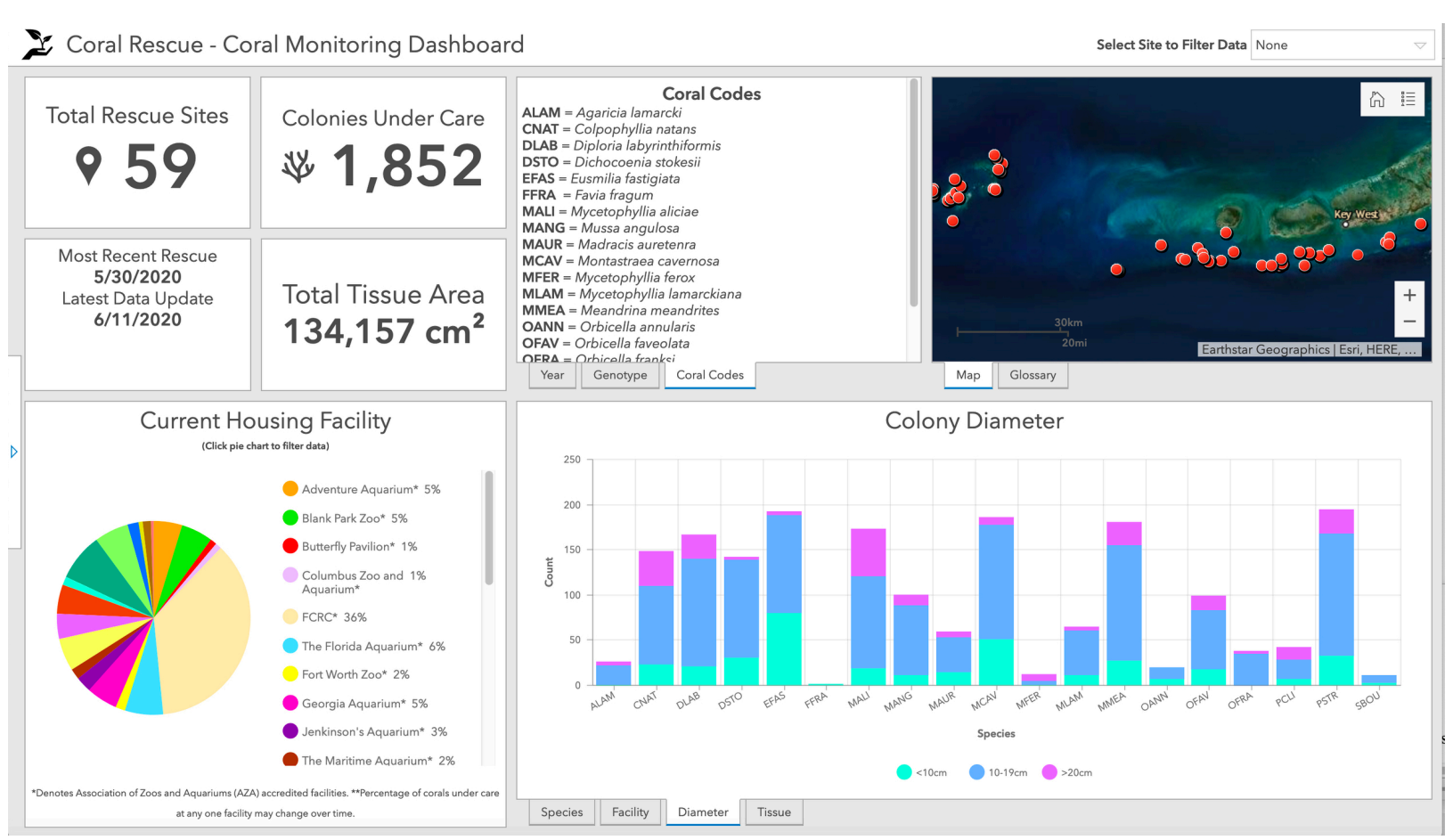

Figure 2: Coral Rescue-Coral Monitoring Dashboard. Screenshot captured August 1, 2020.

Source: FWC Fish and Wildlife Research Institute.

database itself, the corals' lives are translated to readable data (Jue 2020) and, in turn, serve to organize human responses and shape protocols. In this way, these media - and the corals in their agential aspects-materialize the performative interests of rescue, care, and restoration.

The photo series and the Dashboard are conjoined complex systems that connect the corals to the humans seeking to care for them. These media are, therefore, a digital human-animal interface that is shaped by the corals' needs, which include clean, clear water, consistent temperatures, and sunlight. The interface supports the rescue team in its efforts to maintain these standards of life for the corals they collect. In short, the Dashboard provides for humancoral interaction that translates corals' needs in a way that humans can understand and act on. These Dashboard-enabled actions also have the potential to generate nonhuman agency if the corals in care successfully reproduce. Here, media are not passive instruments of observation and documentation but digitally embedded intermediaries that facilitate and monitor care. The domains and agencies of the human and nonhuman can intertwine and interact via these intermediaries: they articulate the corals' needs, define the human rescue and care protocols that respond to those needs, and hold humans accountable for the health of the corals.

The Dashboard's architecture reflects the protocols that govern all stages of field operations, transportation, and care. Its architecture thus centers corals as a primary agent. Together, the Dashboard and the photo series are capacitybuilding environmentalist practices, coupling the complex systems of corals 
rescued from the wild with the humans who care for them. The notion of the "coupling" of the animal with the human via the medium of the Dashboard is critical here. As Erica Robles-Anderson and Max Liboiron describe it, coupling acknowledges the unknowns inherent in a new configuration, and adopts it anyway. As I see it, this particular coral-human coupling is intermediated by the Dashboard, which shifts the stakes further from "knowledge accumulation models that trade upon representational completeness and towards more performative interests" - namely, coral care and restoration $(2016,257)$. While intertwining species more closely with humans-and accepting that the intertwining can only ever be partial - these media facilitate a system of care that works through the disaster of coral loss. They are also an early instantiation of a replicable sustainable ecological process: the technical ability to network within and between situated knowledge hubs and across large geographic areas.

Reefs for their part are a patchwork of genetically unique coral species that are inherently collaborative and intertwined: bony corals, with polyps at the outer surface, are connected by soft and vibrantly colored tissue, which lives in symbiosis with photosynthesizing algae that provide its nutrients (Shick 2018). As Irus Braverman points out, reef-building corals-a continually changing assemblage that she calls "coralations" (2018)-are characterized by their imbrication with other life forms. The Dashboard extends this imbrication across the barrier of the water's surface, inviting humans to entangle with these coralations.

From the perspective of Donna Haraway's theory of situated knowledges, one could say that traditional coral science monitoring has served to distance us from corals and their everyday life cycles by operating through knowledge systems invested in image fidelity and accumulation. The Dashboard is different, and more in keeping with Haraway's "feminist empiricism" in that it applies and holds historic knowledge accountable and makes meaning from offering the corals a chance to live. Then, with the purpose to restore coral reefs, it "allows us to become answerable for what we learn how to see" (Haraway 1988, 583). The credibility of the Dashboard and Flickr media lies in the functional ability of these technologies to align data collection, activities, and research with the needs of the individual corals in care. The outcome is a holistic data management framework ("Data Management Team" 2020) that begins to sketch partial perspectives of a coral future for which humans are accountable. This critical practice affects how knowledge is produced and applied, and positions care as a model for networking reef restoration projects across power-differentiated communities (1988). This digitally materialized, actionable, and mutually generative system of genotypes, propagation, and restoration becomes a model of human-animal care. 


\section{Protocol-Defined Coral Collection, Documentation, Transportation, and Housing}

The Dashboard manifests a central response to the chaos and uncertainty of the SCTLD disaster by mitigating, as far as possible, the stresses to the corals' vital signs. This mitigation occurs through the protocols that govern all rescue and collection work, which must be conducted under a Sanctuary permit. The Flickr series illustrates these protocols for the field collection of corals from the wild and the pencil and paper method of collecting field data, both of which come from the Field Manual for Investigating Coral Disease Outbreaks (Woodley et al. 2008).

Collection from the wild begins with visual identification of healthy priority coral colonies, usually reef-building corals at high risk of infection and corals on the endangered species list at a given reef site. One diver prepares the corals for rescue by removing them from the reef with a hammer and chisel. A second diver photographs the corals with a numbered plastic tag that serves as their unique ID for tracking the species and collection site (figure 3), then transports the corals in bags back to the boat. During the boat ride back to the dock, the corals are attached to terracotta tiles with epoxy glue to help stabilize them, protecting live tissue from damage, and are further documented and sampled. Once they reach land, the corals are secured in temporary holding tanks, where they remain in quarantine until they are certified as free of the disease. When they receive a clean bill of health, the corals are shipped to housing facilities. The data yielded by the collection process is entered manually into the Dashboard database.

The narrative that commonly drives coral collection is one of loss, according to Ursula Heise. A sense of mourning is evoked by narratives of extinction (2016). However, the Dashboard tells another story-one not of loss and mourning but of a hopeful future that can be brought about through careful, scientific intervention. It embodies the mandate to "conserve and protect the genetic diversity of Caribbean coral species" (Florida Fish and Wildlife Conservation Commission n.d.). Each entry in the Dashboard materializes and monitors practices of care provided to the living corals. These practices of care enable corals to continue their reproductive cycle, producing baby corals (planula) that will, it is hoped, grow into successful captive colonies that can be replanted in the wild. As the actualization of María Puig de la Bellacasa's speculative exploration of "how to care" (2017, 41:1503), the Dashboard replaces narratives of extinction with the possibility of life; it offers a new framework of care emblematized by the decision to remove healthy corals from the dying reef and to take long-term responsibility for their health and welfare.

Care does not always shape the response to anthropogenic global problems such as the impacts of climate change (Puig de la Bellacasa 2017) on coral reefs. Often, the response is to collect more information, conduct further research, and explore new technological solutions-to monitor as things die rather than 

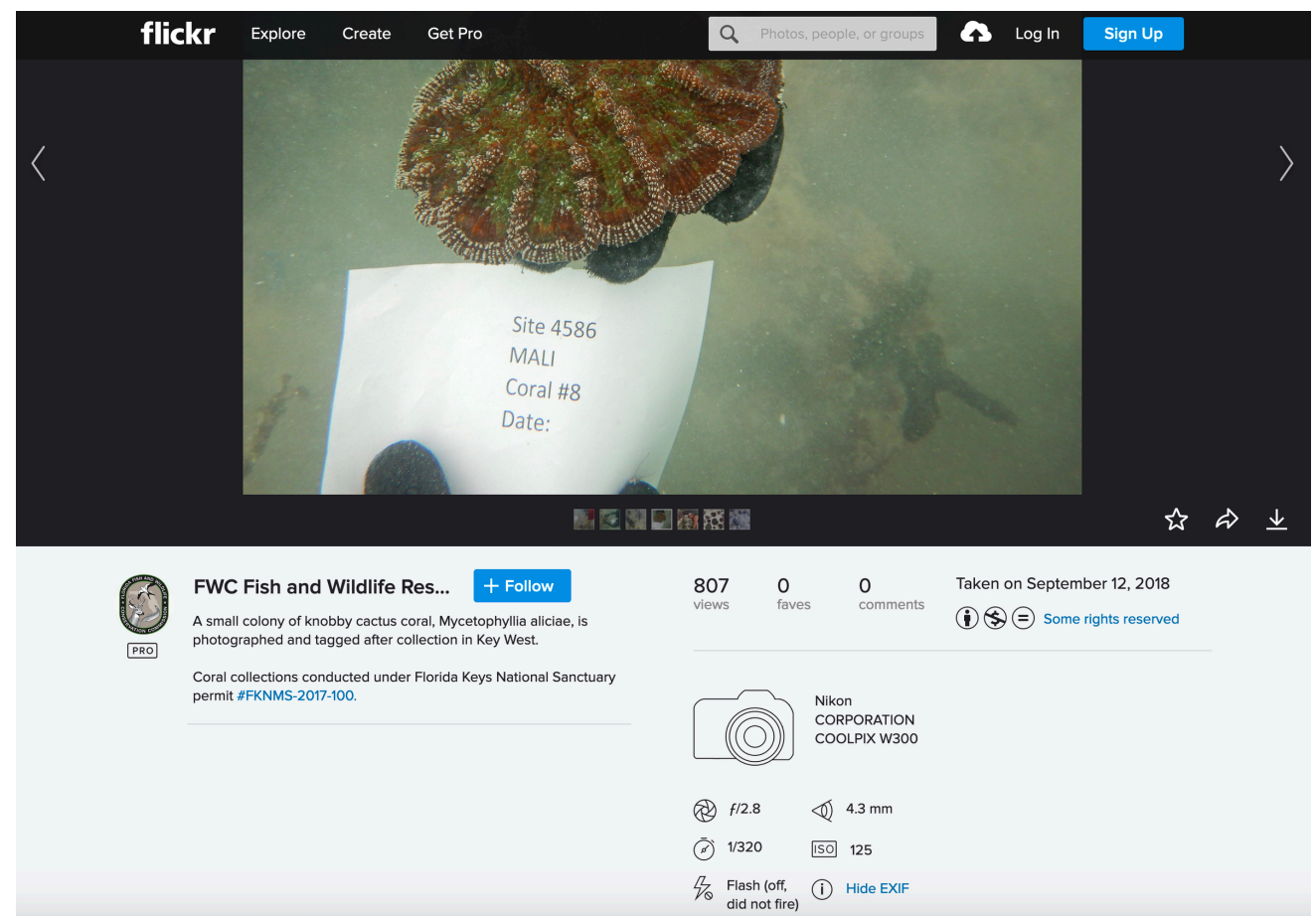

Figure 3: Coral no. 8 at rescue site 4586. Photo by FWC Fish and Wildlife Research Institute, taken on September 12, 2018.

Source: FWC Fish and Wildlife Research Flickr Account. NonCommercial-NoDerivs 2.0 Generic (CC BY-NC-ND 2.0).

to intervene to save them. These two competing responses are described by Braverman, who interviewed scientists responding to a disease outbreak at East Flower Garden Bank within a marine sanctuary in the Gulf of Mexico. Braverman noted these two debates in the scientific community as the use of monitoring for knowledge acquisition for the purpose of prevention and monitoring as a tool that can trigger a more immediate intervention in mortality events (2018). Within the ethics of care, a monitoring system cannot fully address the disaster if it prioritizes knowledge collection over the needs of the infected corals left to struggle without the activity of care. As a part of an ordered human-coral interactive process, the Dashboard translates corals' needs in a way that humans can understand and act on. The Dashboardenabled action thus affords the possibility of nonhuman agency in the form of reproduction. This shift from observation to intervention creates new kinds of dependencies. A protocol-defined ethic of care for this rescue means that participating aquariums and laboratories have agreed to perform monitoring that includes watching, recording, and providing relief to the corals, as per their Sanctuary permit, with an intended outcome of maintaining species and genetic diversity. In these particular aspects that I have been describing, the Dashboard exists as a human-nonhuman "intermediation monitor" that entwines coral work with the everyday functioning of the newly agented corals and, in the entwining, holds humans accountable to maintain a standard of relief from anthropogenic climate change in the wild and in land-based aquariums. 
A companion to the Coral Rescue-Coral Monitoring Dashboard, the Coral Disease Intervention Dashboard is a newer intermediation monitor of the progress of almost three thousand infected corals that remain at reef sites and receive a range of proven and experimental treatment (FWC Fish and Wildlife Research Institute 2020a). This new dashboard and the Coral Rescue-Coral Monitoring Dashboard under discussion here provide summaries of care, for although the disease response does separate the rescue of healthy corals from the treatment of diseased corals, it delivers consistent care to both groups. Again, this displaces the narrative of extinction in favor of Puig de la Bellacasa's speculative exploration of "how to care" $(2017,41: 1503)$. As will be closely examined below, here, care is an actualized approach, which grows out of a different way of thinking about disaster media, intervention, and the practice of knowledge accumulation. The rescue and care for healthy corals in captivity and the treatment and care for infected corals in the wild are conjoining complex systems, both governed by standards of care enforced by permit and protocol-framed monitoring. Rather than merely monitoring the corals' response to disease, natural disasters, and climate change, collecting data as they sicken and die, these dashboards constitute knowledge accumulation to facilitate their transition through recognized practices of care designed to conserve and protect their genetic diversity. The Flickr photo series documents the rescue team's compliance with the protocols outlined in the Field Manual, representing the step-by-step action response-the processes and activities of care. The Flickr series situates the day-to-day life rhythms of the nonhuman, showing both the living animals and the field operation protocols that translate the corals' lives and needs into data for entry into the Dashboard. The images document the shift in perspective described above, depicting the rescue team removing corals from the disease path and placing them in care.

\section{Coral Processing and Translation to Information}

Each of the rescued corals currently in care has a plastic ID tag (measuring approximately two by two inches and containing the site, species, and date) attached to its terracotta tile with a zip tie. Once the corals reach the rehabilitation site, they are placed so that the tags are visible from the surface of the shallow aquariums where the corals live. The data from the ID tag, entered into the database by the Data Management Team, enable anyone to track corals from the originating reef site to the housing facility. A number of the photos in the Flickr series show tags with the rescue site, species, assigned number, and date of rescue visible, matching their records in the Dashboard (figures $\underline{4}$ and 5).

Coral colony no. 8, for example, was rescued from site 4586 on September 12, 2018, and is currently in care at the Florida Aquarium. In figure 3, the cluster of corals is represented in the process of rescue. The description reads, "A small colony of knobby cactus coral, Mycetophyllia aliciae, photographed and tagged after collection in Key West” (2018). Toggling over to the Dashboard, this colony can be located using the filter function to reveal its species, size 


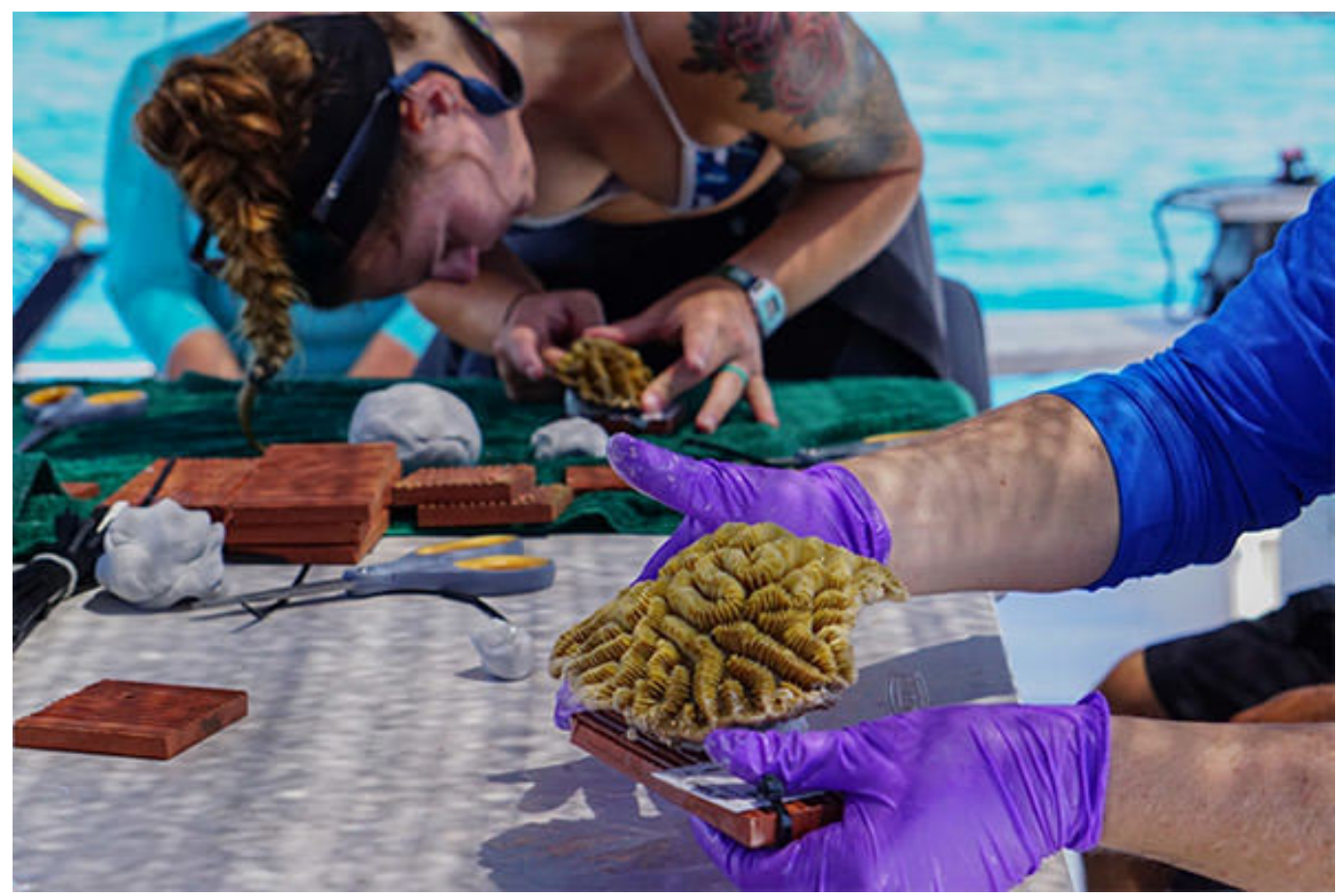

Figure 4: The description reads, "A Montastraea cavernosa is mounted and receiving its tag before being placed into the holding bin onboard the Makai." Photo by Jennifer Moore/NOAA, taken on May 19, 2019.

Source: FWC Fish and Wildlife Research Flickr Account. NonCommercial-NoDerivs 2.0 Generic (CC BY-NC-ND 2.0).

(diameter, height, and width), and tissue surface area, as represented in figures $\underline{6}$ and $\underline{7}$. The Flickr album data show how corals are documented at the site and transformed into information: first analog information, on paper, ID tags, and photos, and eventually digital information in the Dashboard database.

The Dashboard reassembles the individual characteristics of coral reality filtered through scientific knowledge into a collaborative human expression of care. Of course, the model of the reef that we can read on the Dashboard is lowresolution and necessarily incomplete, for it can act only as an intermediation monitor of individual corals; it cannot replicate the relationships among them. Corals, both the live corals in care and their representations within the database, do not have the same opportunities to aggress and compete as in the wild. However, the database does convey the heterogeneity of each reef site. Each reef is a unique patchwork of colonies of corals, and each colony has individual characteristics that differ from the colonies around them (Keller and Wilmot 2008). The Dashboard also organizes and makes visible human activities that serve the corals - the specifics of daily aquarium care, research, and practices designed to protect and conserve the corals' diversity. The Dashboard is an expression of coral agency and human response, which is "facilitated by identification with our surrogates on screen and their point of view" (Smaill 2016, 129). Displayed by the Dashboard interface, we can view and empathize with the material accumulation of individual living corals from multiple reef sites. 


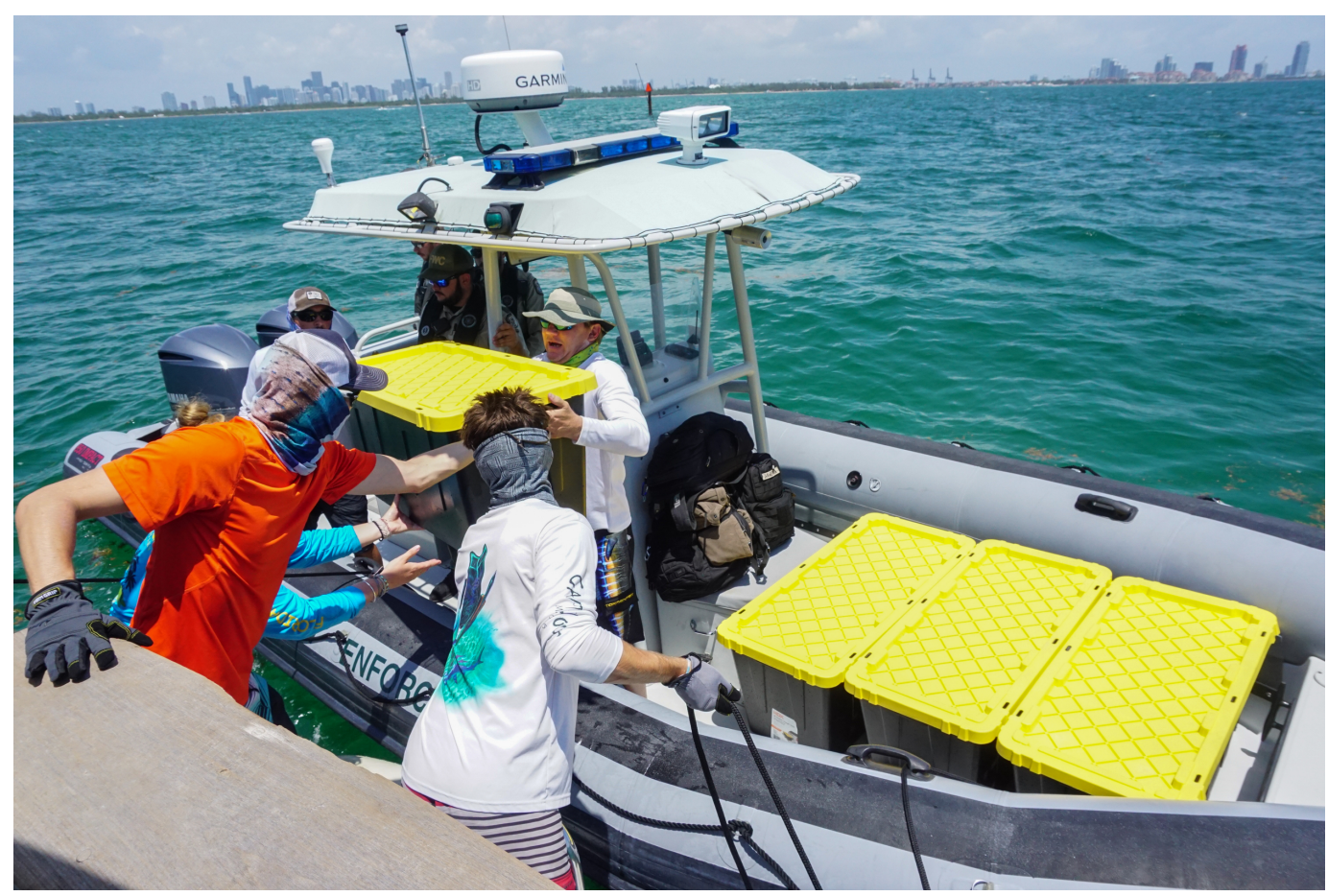

Figure 5: The description reads, "From the Marquesas Keys coral rescue cruise - Captain Joe Bailey, FWRI staff Allan Anderson, Ananda Ellis, Nathan Berkebile, and Callaway Marine Technologies staff Charles Callaway and Turner Hughes carefully move totes filled with rescue corals from the M/V Makai to an FWC Law Enforcement vessel for transport into shallow water near the University of Miami hatchery where the corals are held.” Photo by FWC Fish and Wildlife Research Institute, taken on May 6, 2019.

Source: FWC Fish and Wildlife Research Flickr Account. NonCommercial-NoDerivs 2.0 Generic (CC BY-NC-ND 2.0).

Ursula Heise expresses the principle of empathy through visibility in her work on ARKive.org (2016), a now-defunct ${ }^{1}$ archive of film and photography representing wildlife. Designed to educate audiences and engage them in the conservation of vulnerable species, the ARKive catalogue presented animals as worthy of protection by evoking an intimate experience with them. Its lush visual representations, the site posits, connect us to conservationists' knowledge about these animals and why they are at risk. As Heise notes, such a catalogue may serve as a new way to organize experience into a form of modern epic, but it does not produce meaningful results (2016) in addressing the needs of the animals. While the Dashboard is similarly a catalogue and an organizational tool for endangered species-related information, it produces actionable results. The database uniquely redirects the "enumerative logic" (Heise 2016) of the visual archive, such as the ARKive catalogue, reassembling animal data into an organizational structure of protection that tracks and taxonomizes our knowledge about the corals' health through the human response to their needs. United in service as an intermediation monitor, the Dashboard and the Coral Rescue Flickr photo series are lush data more than lush imagery and as such provide information necessary to maintain corals' standard of care. 


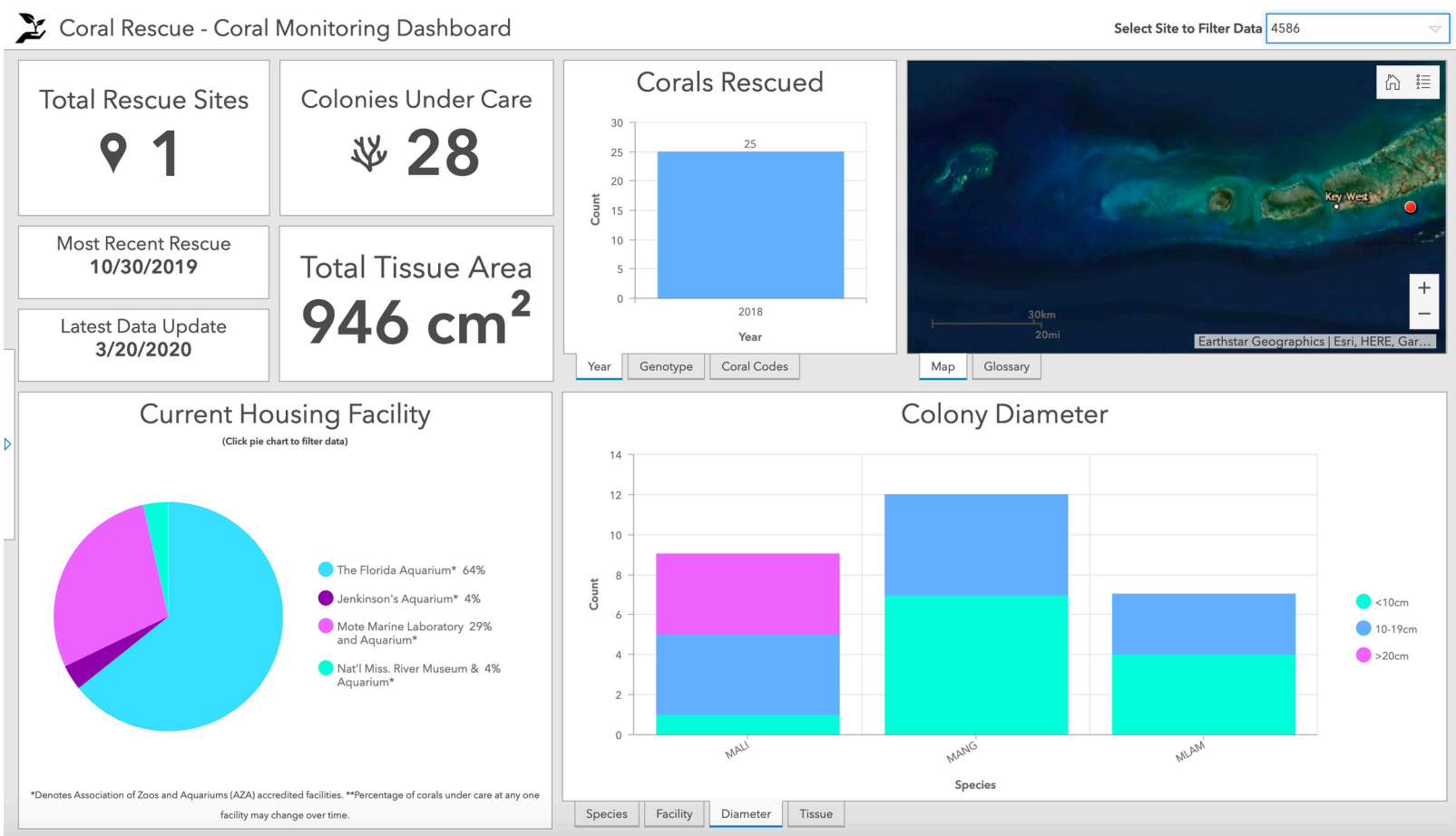

Figure 6: Coral Monitoring Dashboard, search site to filter data to site 4586. Screenshot captured August 1, 2020.

Source: FWC Fish and Wildlife Research Institute.

The Dashboard form favors variability and measurement, capturing the vital signs of corals and treating each coral characteristic as equally crucial to that goal. The corals' total diameter and tissue area are distinguishing features, critical components of the master goal of restoring reefs. Coral no. 8 (figures $\underline{6}$ and 7 ), for example, is recorded as having a diameter of eleven centimeters and a tissue surface area of twenty-nine square centimeters. The numerical data are not entirely stable, for the coral colony is alive and growing, and its diameter and surface area change. However, protocols dictate that these particular data not be updated (2020), as this would require caregivers to handle the corals, stressing them and potentially impacting their continued growth and sexual maturation.

The Dashboard tells a story of addition — growth in numbers—rather than the story of subtraction told by narratives of disaster and extinction. That is not to say that the story is always one of growth. In March 2020, the total number of rescue sites changed from forty-two to forty-one, and 326 of 1,748 corals reported as rescued in November 2019 had disappeared from the Dashboard by March 2020. Given that the data maintained in the Dashboard tracks sites ahead of the disease and documents disease-free corals, this drop suggests that a site was infected. However, the Coral Rescue Dashboard instructions describe rescue as "a comprehensive plan to rescue susceptible coral species from both impacted and unimpacted reef systems in Florida, [and] maintain these in exsitu aquaria and laboratory facilities" (2020b, emphasis mine). One hopes that these corals might have simply been transferred to a different system of care. 


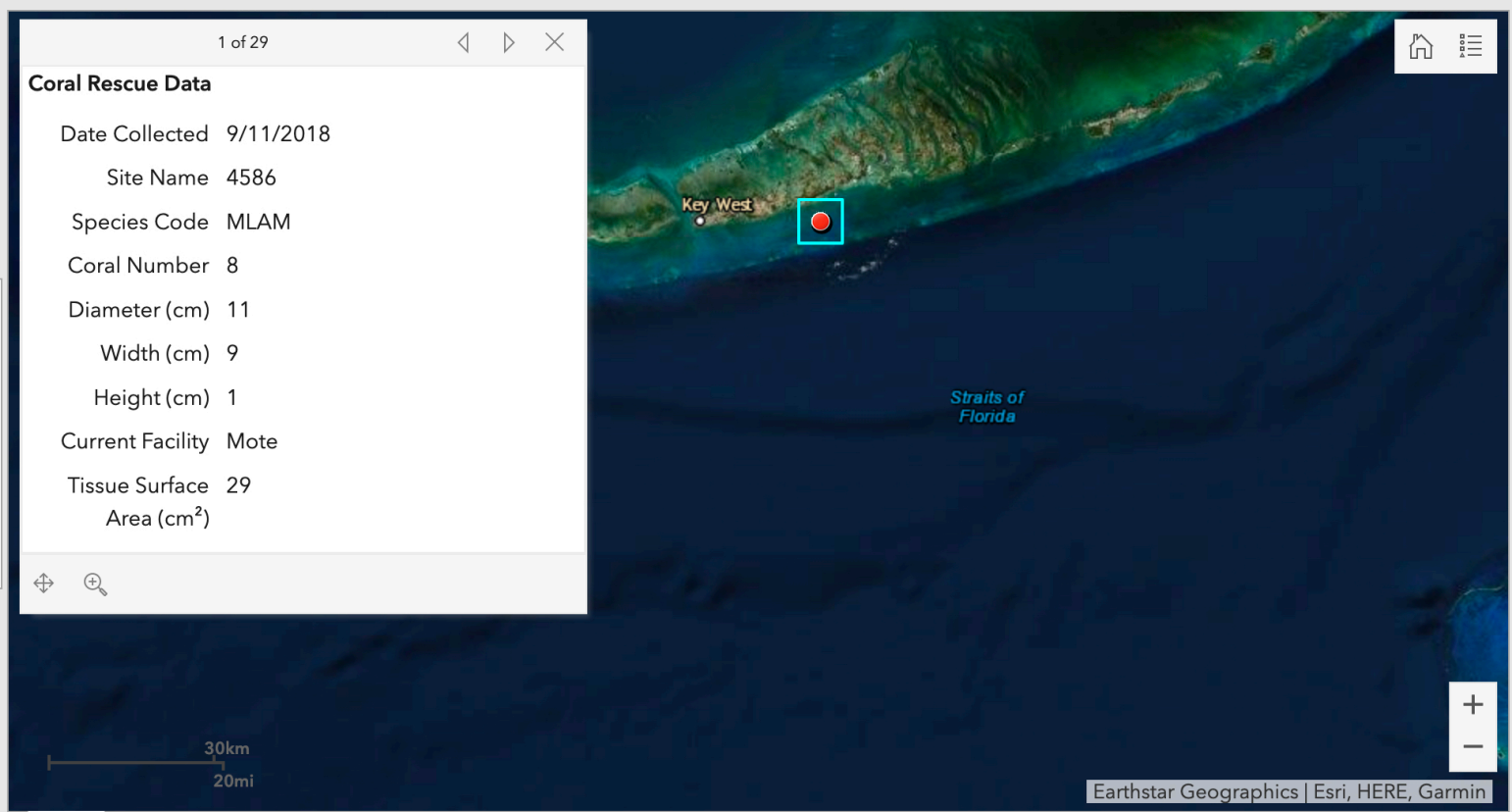

Figure 7: Coral Monitoring Dashboard, search site to filter data to site 4586. Map expanded and field site window opened to coral no. 8. Screenshot captured August 1, 2020.

Source: FWC Fish and Wildlife Research Institute.

Each coral's data-date collected, site name, species, and number-is collected on-site and recorded on its unique ID tag (Figure 3), then immediately transcribed onto a paper spreadsheet. Within about two weeks, the data are manually typed into the administration side of the Dashboard. These pencil and paper collection protocols follow those outlined in the Field Manual. Once entered, Esri's proprietary location analytics application synthesizes the data on a shared map. Each point on the map represents a rescue site and records for each of the corals now in care at that site. Each record shows a unique number, the coral species, its size and tissue area at the time of rescue, and the current housing facility. These data express what researchers learn from corals in the field and the lab.

Whereas the Dashboard tells the story of care through empirical measurement and spatiality, the Coral Rescue Flickr photo series shows the qualities of human action: researchers removing corals from a reef site, documenting corals, sampling genetic material for tagging, and setting corals in temporary aquariums. This contextual data frames the rescue. As the photo series visually defines these microsteps in the rescue plan, it also represents the potential capacity of documentary photography, paired with an interactive database, to generate anticipation. The photos invite people to "participate visually in the sights of scientific work" (Landecker 2006, 123). The series includes 102 timestamped images of the fieldwork activities (figures $\underline{\underline{3-5}}$ ): we see bodies bent over in service, faces often obscured, and hands turned toward acts of care-related labor. The scientists are not posing with the corals in a moment of leisure; they 


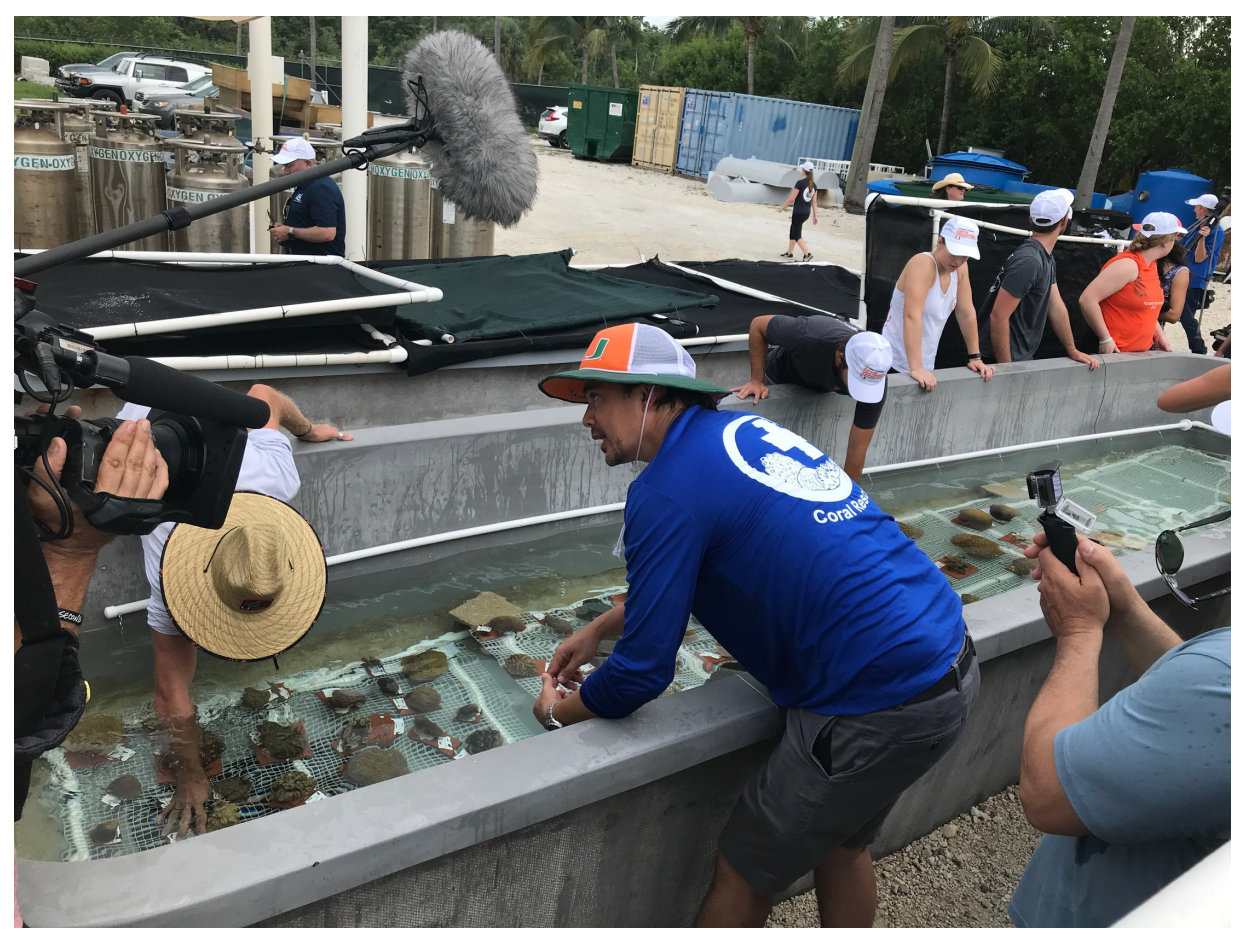

Figure 8: Image 2822. Photo by FWC Fish and Wildlife Research Institute, taken on July 5, 2019.

Source: FWC Fish and Wildlife Research Flickr Account. NonCommercial-NoDerivs 2.0 Generic (CC BY-NC-ND 2.0).

are shown acting on the coral information, performing the series of protocols necessary to their survival. The granular field report documentation (represented by the image of coral no. 8 embedded in the Flickr album page) intertwines with the media technology. Each image represents a pivotal moment in the life story of the corals, scaling the story of decline from global catastrophe to the data-rich intermediation monitoring of a single coral colony in its passage from site 4586 to the Florida Aquarium. These rich visual and contextual images are "modes of knowledge [that] are embedded, passionate, and purposeful-the mirror image of scientific objectivity" (Alaimo 2012, 561).

The collection of coral no. 8 is pictured, showing the small coral colony in the gloved hand of a member of the coral rescue team (figure 3 ), evoking ideas of care for small and vulnerable beings. However, figures $\underline{3}$, $\underline{4}$, and $\underline{8}$ show us the limitations of rescue. Coral colonies can grow quite large and live indefinitely (Shick 2018). However, only those smaller corals that can be easily removed from the reef, transported, and successfully cared for in aquariums are part of this rescue. For example, "Big Momma," one of the largest known colonies of mountainous star coral, estimated to be 330 years old and having survived hurricanes and industrialization, was too physically large to place in ex-situ care and died within approximately three months of infection ("Florida Reef Tract Coral Disease Outbreak: Response.” Florida Keys National Marine Sanctuary” n.d.). While this colony died before this rescue response, in-situ 
treatments are monitored through the Coral Disease Intervention Dashboard. Intervention teams follow the same protocols of care as rescue teams, but with the acknowledgment that the care is palliative and experimental.

While we cannot see coral no. 8 directly in care at the Florida Aquarium, the data characterizes this living creature on a material cellular level, whose function is indexed by genotype and changes in tissue area and size. Unlike a photographic catalogue, which captures the likeness of an endangered species at a single point in time, the Dashboard database allows us to connect with the corals as living beings in the process of living. The database upon which the interface is built is permeable, meaning the data fields accommodate coral growth and death; changes in data are produced by the corals themselves, which are primary agents. Implicitly embedded in the Dashboard, it is care that subtends the corals' long-term health. Care is measured by the historic records of coral abundance, diversity recorded in the database, and biological functioning.

The Dashboard and the Coral Rescue photo series signal both permanence and anticipation. According to anthropologist and filmmaker Juan Francisco Salazar, documentary films make it culturally possible to participate in the future by performing socio-ecological change (2018, my emphasis). While the Dashboard and the photo series do not comfortably fit within the category of documentary cinema, they serve a similar function: to offer what Salazar describes as possibility that "may be understood as the capacity to shape the future as embodied experience" $(2018,45)$. By materializing coral agency, the Dashboard and the photo series make present the future of a restored reef within a care ethic of responsibility.

The Dashboard also represents the reef as we see it from satellite images, as a digitally networked hub of corals' situated knowledges. Red dots represent clusters of field data (figures $\underline{6}$ and $\underline{7}$ ). The database structure allows these data to be combined and reconceived (Jue 2020) and enables researchers to see cluster sites as part of the more extensive reef network. The red dots of the rescue reef sites are logistical components brought together to help to produce the systemic relationships among corals, technology, and humans. This coral collectivity condenses the cycle from life to data to care to life (Haraway 2016). As applied earlier, situated knowledges make us accountable for what we learn how to do (Haraway 1988). The Dashboard, as a situated nonhuman-technical-human project, makes things, such as situational information; it also makes things happen, as when that situational knowledge enables researchers to respond - to be response-able (2016) — to the corals.

To recognize coral's ways of knowing requires the responsiveness of human attunement. The editors of the report Connectivity: Science, People, and Policy, who are both employed by the Florida Keys National Marine Sanctuary, note in their introduction that, produced by knowledge and attunement, "the connectivity between people and marine resources is most obvious to those 


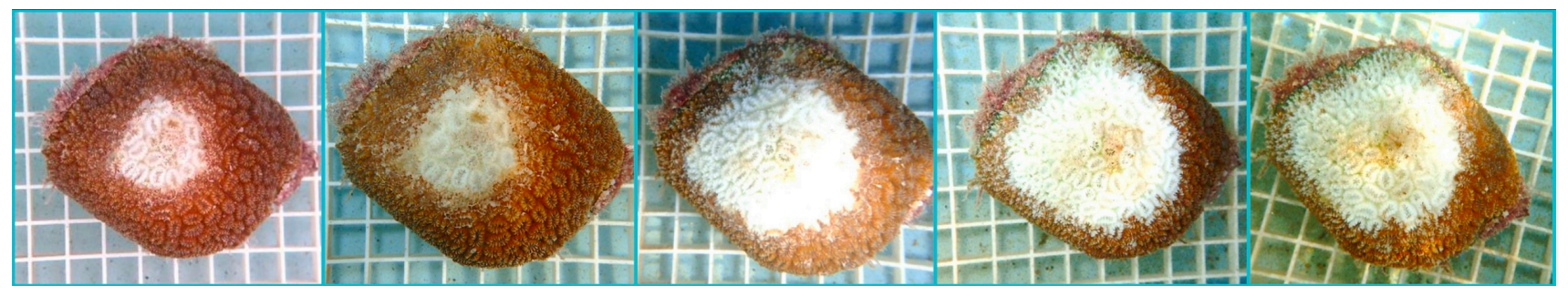

Figure 9: "Time series photos over five days show the rapid tissue loss on an infected coral." Photo by Karen Neely, Nova Southeastern University, nd.

Source: NonCommercial-NoDerivs 2.0 Generic (CC BY-NC-ND 2.0).

who make their living from the ocean; they know how complex it is" (Keller and Wilmot 2008, 7). This connectivity is produced in part by acts of caring, which are themselves products of hope. Karen Neely, a marine scientist, cares for corals across the spectrum of coral health. Neely, who photographed five days toward the end of the life of infected corals (figure 9), has studied corals in the Caribbean for nineteen years. Her photographs share her knowledge of and attunement to corals in sickness and in health; she monitors corals' decline, treats and cares for wild corals, and fosters the spawning of rescued corals (Changing Seas 2019). Her work is hope in action.

\section{Humanitarianism Remodeled for Human and More than Human Relations}

Hope is a form of engagement with past and present environmental constraints, and attunement-a nature-human relationship in which the human is attempting to interpret a loss of nature (Shewry 2015) - that produces and prioritizes the agency of the nonhuman. Belinda Smaill shows that this privileging of nonhuman agency can be accomplished through representational media. By providing the impression of ecological existentialism that "underpins and questions the very meaning of the human," says Smaill, "this worldview subjugates human agency to the process of the ecosystem" $(2016,130)$. In an era of rapid and unprecedented environmental emergencies, the ethic of care for both humans and corals requires ecosystems thinking-predisaster care in the form of logistical response plans for the pragmatic deployment of resources that anticipate and materially mitigate impacts (Munslow and O'Dempsey 2010). This hands-on response forces a kind of ecological thinking, showing humans our embeddedness in the earth's past and present (Smaill 2016). The Dashboard forces the same kind of ecological thinking. Its reordering of the microscale habitat of individual corals allows us to grasp the macroscale ecosystem of a living reef-to think about the minute characteristics of a single coral colony and to abstract from those an astronaut's-eye view of the 358 linear mile reef site (Jue 2020).

As this article has discussed, the practice of anticipating environmental disasters with planned logistical response mechanisms grows out of an humanitarian ethic of response to nonhumans in need. It can shift our focus: 
during this disaster event, we do not sense the stony coral tissue loss disease but the corals themselves, for their needs must guide our planned logistical responses. The corals emerge and change in ways that humans have made intelligible to ourselves through the Dashboard and the Coral Rescue Flickr photo series, which serve as a digital human-animal interface. The configuration of these two tools materializes the agency of the nonhuman as a digital record of coral living and dying, and helps to define the standard of care needed to mitigate a coral disease disaster.

The Dashboard and the photo series ask us to think in terms of processes rather than outcomes. They render the current disaster of coral disease as one event in the life of the corals rather than the end of life, and convey the standard of care that entwines the corals with their caregivers. In this capacity, the Dashboard and the photo series exemplify the "disaster media" paradigm set out by Parks and Walker (2020). As the Dashboard transitions from intermediation monitoring of rescue to care with successful restoration activities (as with the 2020 nursery-raised staghorn coral outplant spawning event), and simultaneously holds us accountable for the anthropogenic contributing factors-a warming planet, development, pollution-it extends disaster media from a response to a standard that provides the necessary relief for survival.

While the disease threatens corals remaining on reefs in its path, the disease is not the only threat; corals also die when humans do not carry out their ethical responsibilities. To ensure that we meet these responsibilities set out by the Sanctuary and the NOAA established protocols of care, these media materialize and formalize the duty of care required of the coral rescue team.

Like the rescue teams, coral housing facilities are bound by the same protocols of care expressed through the Dashboard. These facilities, most often associated with the Association of Zoos and Aquariums (AZA), must have permits from the Sanctuary; this accreditation ensures that they follow the mandated protocols of coral care. Moreover, the protocols of coral housing facilities are successfully helping the corals thrive: in April 2020, the Florida Aquarium, an AZA member, announced that ridged cactus corals rescued from the reef more than a year ago reproduced for the first time in a controlled laboratory setting ("The Florida Aquarium Makes History Again!” 2020). The Dashboard has contributed to the protocol-defined rescue and care procedures and a public accounting for the practice of an interspecies ethic of care.

The Dashboard data-that digital embodiment of the corals-is being felt far beyond the Florida Reef in which it is grounded, and by audiences other than the scientists it primarily addresses. At the Coral Futures symposium, people gathered from thirty countries to discuss coral science and management across disciplines. At this symposium, I observed Richard Vevers, CEO and founder of the Ocean Agency, underwater photographer and producer of the film Chasing Coral (2017), actively participating in discussions with scientists. 
I interpret these exchanges as an indication of a new type of collaboration across disciplines to produce science-based coral narratives to be shared with the public. Vevers sees his work as a form of nonprofit advertising. He counts among his clients both the ocean itself and corals specifically, including those in the Coral Restoration Foundation nursery and outplant areas. His current work includes creating portfolios for reefs that demonstrate resilience to coral bleaching and bringing together collaborating partners to fund and participate in conservation and propagation initiatives ("50 Reefs Initiative: A Global Plan to Save Coral Reefs and a Huge Win for Their Conservation.," n.d.). These are new types of coral rescue and care, enacting "the need to be more civil to the environment, particularly of the need to take personal responsibility for protecting our marine resources" (Keller and Wilmot 2008, 7). Here, care is the concrete expression of the ecological thinking and ethics of care that we learn via human-coral interactions.

The Coral Rescue Flickr photo series (n.d.), too, engages in seawater thinking (Jue 2020) that enlivens the data-driven coral response. It reconciles the scale and abstraction (2020) of the Dashboard with corresponding visual records of human interaction with the corals above and below the surface (figures $\underline{3-5}$ and $\underline{8}$ ). Magnifying the time and space of rescue activities and rescued corals, the photos show otherwise ephemeral moments of fieldwork that cross the water surface boundary. The narrative of hope offered by the photo series is reinforced with evidence in the form of accessible and visually presented scientific data and analysis, field activities, mapping, and human attunement.

The entire original reef cannot be saved from the disease, for resources-time, people, and money-are limited. The Dashboard and the Flickr series emphasize the transparency and democracy of scientific data; they signal an emerging institutional approach that amalgamates conservation with intervention to prioritize the corals as agents and anticipate the long-term building of a relationship with a reef in progress (now only imaginary). The media configuration of the Dashboard and the photo series enables a coherent and complex flow of information through the circuit of corals, rescue actors, and caregivers. It materializes the cultural response that is shifting away from seeing the environmental disaster as an end and toward treating it as one marker of corals' identity within a life cycle. Even with this new response, the future of corals is yet to be determined.

\section{Dedication}

In memory of my father Paul James who lovingly pointed me back to the ocean.

This is an open-access article distributed under the terms of the Creative Commons Attribution 4.0 International License (CCBY-4.0). View this license's legal deed at http://creativecommons.org/licenses/ by/4.0 and legal code at http://creativecommons.org/licenses/by/4.0/legalcode for more information. 


\section{REFERENCES}

"50 Reefs Initiative: A Global Plan to Save Coral Reefs and a Huge Win for Their Conservation.” n.d. The Ocean Agency. https://theoceanagency.org/50reefs.

Alaimo, Stacy. 2012. "Sustainable This, Sustainable That: New Materialisms, Posthumanism, and Unknown Futures.” PMLA 127 (3): 558-64. https://doi.org/10.1632/pmla.2012.127.3.558.

Bicker, L. 2019. “Genetic Bank.” Tavernier Nursery Map. Coral Restoration Foundation. https://www.coralrestoration.org/restoration.

Braverman, Irus. 2018. Coral Whisperers: Scientists on the Brink. Kindle edition. Oakland: University of California Press. https://doi.org/10.1525/california/9780520298842.001.0001.

Changing Seas. 2019. “Episode 1103 Corals in Crisis.” South Florida PBS 26 (June): 42. https://doi.org/10.1038/s41567-019-0720-4.

"Data Management Team.” 2020. Florida Department of Environmental Protection. https://floridadep.gov/rcp/coral/content/data-management-team.

Florida Fish and Wildlife Conservation Commission. n.d. "Coral Rescues: Staying Ahead of the Disease.” Accessed August 7, 2020. http://myfwc.com/research/habitat/coral/disease/rescue/.

"Florida Reef Tract Coral Disease Outbreak: Response.” Florida Keys National Marine Sanctuary." n.d. Accessed April 28, 2020. https://floridakeys.noaa.gov/coral-disease/response.html.

FWC Fish and Wildlife Research Institute. 2020a. "Coral Disease Intervention Dashboard." https://myfwc.maps.arcgis.com/apps/opsdashboard/ index.html\#/55a759f02f3c486eb1d29a95f80fba0a.

_-_. 2020b. “Coral Rescue - Coral Monitoring Dashboard.” Last Modified, March 20, 2020. http://myfwc.maps.arcgis.com/apps/opsdashboard/ index.html\#/eba7dc2cabc64f60819e6d4b084d94cd.

“Genetic Bank.” n.d. Science. Coral Restoration Foundation. Accessed April 19, 2020. https://www.coralrestoration.org/science.

Haraway, Donna. 1988. "Situated Knowledges: The Science Question in Feminism and the Privilege of Partial Perspective.” Feminist Studies 14 (3): 575-99. https://doi.org/10.2307/3178066.

- - . 2016. Staying with the Trouble: Making Kin in the Chthulucene. Kindle edition. Durham: Duke University Press. https://doi.org/10.1515/9780822373780.

Heise, Ursula K. 2016. Imagining Extinction: The Cultural Meanings of Endangered Species. Kindle edition. Chicago: University of Chicago Press. https://doi.org/10.7208/chicago/ 2780226358338.001 .0001$.

Jue, Melody. 2020. Wild Blue Media: Thinking Through Seawater. Kindle edition. Durham: Duke University Press. https://doi.org/10.1215/9781478007548.

Keller, B. D., and F. C. Wilmot, eds. 2008. "Connectivity: Science, People, and Policy in the Florida Keys National Marine Sanctuary.” In Marine Sanctuaries Conservation Series NMS of Commerce. Silver Spring: National Oceanic and Atmospheric Administration Sanctuary Program.

Landecker, Hannah. 2006. "Microcinematography and the History of Science and Film.” Isis 97 (1): 121-32. https://doi.org/10.1086/501105.

Munslow, Barry, and Tim O’Dempsey. 2010. "From War on Terror to War on Weather? Rethinking Humanitarianism in a New Era of Chronic Emergencies.” Third World Quarterly 31 (8): 1223-35. https://doi.org/10.1080/01436597.2010.542965.

Parks, Lisa, and Janet Walker. 2020. "Disaster Media: Bending the Curve of Ecological Disruption and Moving toward Social Justice.” Media+Environment 2 (1). https://doi.org/10.1525/001c.13474. 
Parsons, G. n.d. “Florida Reef Tract Coral Disease Outbreak: Media Resources.” In Key Largo: Florida Keys National Marine Sanctuary, Office of National Marine Sanctuaries, National Ocean Service, National Oceanic and Atmospheric Administration, U.S. Department of Commerce. Accessed April 27, 2020. https://floridakeys.noaa.gov/coral-disease/media.html.

Puig de la Bellacasa, María. 2017. Matters of Care: Speculative Ethics in More than Human Worlds. Kindle edition. Vol. 41. Minneapolis: University of Minnesota Press.

REEFocus. 2020. “Breaking News: 14-Month-Old Staghorn Outplants Spawn in the Wild.” August 7, 2020. https://www.coralrestoration.org/post/breaking-news-14-month-old-staghorn-outplantsspawn-in-the-wild.

Robles-Anderson, E., and M. Liboiron. 2016. "Coupling Complexity: Ecological Cybernetics as a Resource for Nonrepresentational Moves to Action.” In Sustainable Media, edited by Nicole Starosielski and Janet Walker, 248-63. New York: Routledge.

Salazar, Juan Francisco. 2018. "Anticipatory Modes of Futuring Planetary Change in Documentary Film.” In A Companion to Contemporary Documentary Film, edited by Alexandra Juhasz and Alisa Lebow, 43-60. Hoboken: Wiley. https://doi.org/10.1002/9781118884584.ch2.

Shewry, Teresa. 2015. Hope at Sea: Possible Ecologies in Oceanic Literature. Kindle edition. Minneapolis: University of Minnesota Press. https://doi.org/10.5749/minnesota/ 2780816691579.001 .0001$.

Shick, J.M. 2018. Where Corals Lie: A Natural and Cultural History. London: Reaktion Books. Smaill, B. 2016. Regarding Life: Animals and the Documentary Moving Image. Albany: SUNY Press. Summerhayes, C. 2015. Google Earth: Outreach and Activism. New York: Bloomsbury Publishing. “The Florida Aquarium Makes History Again!” 2020. (Press Release April 22, 2020). The Florida Aquarium. https://www.flaquarium.org/pressroom/posts/cactuscoral.

Woodley, C.M., A.W. Bruckner, A.L. McLenon, J.L. Higgins, S.B. Galloway, and J.H. Nicholson. 2008. "Field Manual for Investigating Coral Disease Outbreaks." In NOAA Technical Memorandum NOS NCCOS 80 and CRCP 6. Silver Springs: National Oceanic and Atmospheric Administration. 